\title{
Retratação para 'Estudo da viabilidade técnica de implantação de aerogerador de pequeno porte de energia elétrica renovável no Estado de Alagoas.' [Rev. Bras. Gest. Amb. Sustent. (2016), v. 3, n. 6, p. 307-316]
}

\section{Luiz André da Silva Lima, Valéria Loureiro da Silva*}

Faculdade SENAI CIMATEC. Av. Orlando Gomes, 1845. Piatã. Salvador-BA (CEP 41650-010).*E-mail: valeria.dasilva@fieb.org.br.

A Comissão Editorial da Revista Brasileira de Gestão Ambiental e Sustentabilidade (ISSN 2359-1412) vem a público comunicar a retirada formal do artigo

Lima, L. A. S.; Silva, V. L. Estudo da viabilidade técnica de implantação de aerogerador de pequeno porte de energia elétrica renovável no Estado de Alagoas. Study of the technical feasibility of implementation of aircraft of small energy renewable energy in the State of Alagoas. Rev. Bras. Gest. Amb. Sustent., v. 3, n. 6, p. 307-316, 2016. http://dx.doi.org/10.21438/rbgas.030605

a pedido da segunda autora, orientadora da pesquisa, que informou que o artigo submetido e publicado contém erros nos dados que não puderam ser reproduzidos, além de conter várias citações indevidas.

Os autores e a Comissão Editorial lamentam profundamente o ocorrido e desculpam-se por eventuais transtornos causados.

\section{Referência}

Lima, L. A. S.; Silva, V. L. Estudo da viabilidade técnica de implantação de aerogerador de pequeno porte de energia elétrica renovável no Estado de Alagoas. Revista Brasileira de Gestão Ambiental e Sustentabilidade, v. 3, n. 6, p. 307-316, 2016. http://dx.doi.org/10.21438/rbgas.030605
Recebido:

20/11/2017

Aceito:

30/12/2017

Publicado:

31/12/2017

Acesso Aberto Artigo completo

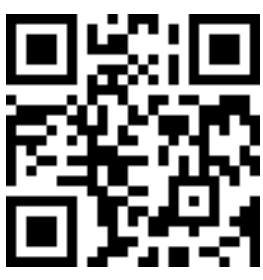

ORCID

(1) 0000-0001-6558-2425 Luiz André da Silva Lima

(1) 0000-0001-5466-7933

Valéria Loureiro da Silva 